\title{
Genotype-dependent associations between serotonin transporter gene (SLC6A4) DNA methylation and late-life depression
}

\author{
Dilys Lam ${ }^{1}$, Marie-Laure Ancelin ${ }^{3}$, Karen Ritchie ${ }^{3,4}$, Rosanne Freak-Poli ${ }^{5}$, Richard Saffery ${ }^{1,2}$ and Joanne Ryan ${ }^{1,2,3,5^{*}}$ (D)
}

\begin{abstract}
Background: Disrupted serotonergic signaling is often a feature of depression and the role of the serotonin transporter gene (SLC6A4), responsible for serotonin re-uptake, has received much attention in this regard. Most studies have focused on the polymorphic 5-HTTLPR upstream repeat, or DNA methylation at the promoter CpG island. Few studies have explored the influence of genetic variation across the gene on DNA methylation, and their combined association with depression risk. The aim of this study was to determine whether genetic variation in the SLC6A4 gene influences promoter DNA methylation, and whether these are associated with depression status.

Method: The ESPRIT study involves a community-based population of older individuals ( $>65$ years of age). Major depressive disorder (MDD) was diagnosed according to DSM-IV (American Psychiatric Association, 1994) criteria, and severe depressive symptoms assessed by the Centre for Epidemiological Studies Depression (CES-D) Scale. Sequenom MassARRAY was used to measure SLC6A4 methylation status $(n=302)$.

Results: Nominally significant associations were observed between SLC6A4 genetic variants (5-HTTLPR, rs 140700, rs4251417, rs6354, rs25528, rs25531) and DNA methylation at several CpG sites. In multivariate regression, DNA methylation was associated with depression status, but only in the presence of specific genotypes. In individuals homozygous for the short 5-HTTLPR and 5-HTTLPR/r25531 alleles, lower methylation at two CpGs was associated with depression ( $\beta=-0.44$ to $\beta=-0.31 ; p=0.001$ to $p=0.038$ ).
\end{abstract}

Conclusion: We present evidence for genotype-dependent associations between SLC6A4 methylation and depression. Genetic variants may also play a role in influencing promoter methylation levels and its association with depression.

Keywords: Depression, DNA methylation, Epigenetics, Genetic variation, Serotonin transporter

\section{Background}

Serotonin deficiency was one of the earliest hypothesis of depression causality $[1,2]$. This came from the discovery of a class of antidepressants, the selective serotonin re-uptake inhibitors (SSRIs), which block the reuptake of the neurotransmitter and therefore increasing its availability. SSRIs are thus commonly prescribed to treat depression, however the response rate remains relatively modest (around 50\%) [3]. The serotonin transporter (5-HTT), encoded by the serotonin transporter gene (SLC6A4), is a principle regulator of serotonergic neurotransmission and

\footnotetext{
* Correspondence: joanne.ryan@monash.edu

${ }^{1}$ Cancer \& Disease Epigenetics, Murdoch Children's Research Institute, Royal Children's Hospital, Parkville, VIC, Australia

${ }^{2}$ Department of Paediatrics, University of Melbourne, Parkville, VIC, Australia Full list of author information is available at the end of the article
}

the active target of SSRIs [4]. Thus, the role of SLC6A4 and its (dys)regulation has been a major focus of depression research.

One feature of SLC6A4 which has been the subject of much research, is the upstream gene-linked polymorphic region, 5-HTTLPR. A $44 \mathrm{bp}$ insertion/deletion variable number tandem repeat (VNTR), results in either short (S) or long (L) alleles. The S allele results in lower SLC6A4 transcriptional levels and therefore reduced reuptake of serotonin $[5,6]$. There is some evidence that 5-HTTLPR genotype affects vulnerability to a broad range of behavioural disorders including depression [1]. However, these associations have not been consistently found [7], suggesting that other regulatory mechanisms and factors are likely to contribute to depression risk [8-10]. 
Approximately $1 \mathrm{~kb}$ downstream from 5-HTTLPR lies another widely studied regulatory element, a CpG island that spans the upstream promoter of exon 1 and the transcriptional start site [11]. DNA methylation of this compact region of $\mathrm{CpG}$ sites has been associated with reduced expression [11]. Previous, generally small studies have investigated the association between depression and SLC6A4 DNA methylation in peripheral tissues, but with conflicting findings [12-20]. It is now clear that genetic variation is an important regulator of DNA methylation across the genome [21], yet only a few studies have examined whether 5-HTTLPR influences methylation and/ or the association between methylation and depression $[15,16]$. To date the effects of other SLC6A4 genetic variants on DNA methylation and on the potential link between depression and methylation, have yet to be investigated.

Using data gathered as part of a large general population cohort study of older persons, this study firstly investigated whether SLC6A4 genetic variation across the gene influences promoter DNA methylation and secondly, whether depression is associated with DNA methylation independently and/or in combination with genetic variation.

\section{Methods}

\section{The ESPRIT study}

Participants included in this study were part of the French ESPRIT study of neuropsychiatric disorders in an older population [22]. Eligible participants aged 65 years and older from the non-institutionalised general population were randomly recruited from electoral rolls within the Montpellier district. Recruited participants to ESPRIT provided written informed consent and were asked to undergo standardized health and psychiatric interviews, as well as extensive clinical assessments. Information was collected on the participants' lifestyle, health and medical use. The study protocol was approved by the Ethical Committee of University Hospital of Kremlin-Bicêtre, France.

\section{Depression measures}

Major depressive disorder (MDD) was diagnosed according to the Diagnostic and Statistical Manual of Mental Disorders-IV (DSM-IV) (American Psychiatric Association, 1994) criteria, using the Mini International Neuropsychiatric Interview (MINI, French version 5.00) [23]. Diagnoses were further reviewed and validated by a panel of psychiatrists and a psychologist with access to information from participants' health assessments. Severity of depressive symptoms was assessed by the Centre for Epidemiological Studies-Depression (CES-D) scale, a self-reporting questionnaire previously validated within the older population [24, 25]. A score of 16 or above is considered the threshold of depressive symptoms warranting further clinical investigation [25]. Thus, late-life depression was defined in this study as having a diagnosis of MDD or high levels of depressive symptoms (CES-D $\geq 16)$.

\section{Genotyping}

Blood samples were collected at recruitment following clinical assessment. In concordance with previous SLC6A4 methylation association studies in blood [12-15, 17, 19, 20], genomic DNA was extracted from white blood cells using a standard procedure [26] and used for genotyping and methylation analysis. Along with 5-HTTLPR, five single nucleotide polymorphisms (SNPs) ( $r s 140700, r s 25528$, rs4251417, rs6354, rs25531) spanning the SLC6A4 gene were also genotyped. These were chosen on the basis of allele frequencies and prior associations with depression $[3,26,27]$. Genotyping of 5-HTTLPR was performed as previously described [26], and SNPs were genotyped by KBiosciences (UK), using the KBioscience Competitive Allele-Specific PCR SNP genotyping system (KASPar) [28]. 5-HTTLPR can also be considered in combination with $r s 25531$, a SNP that lies within the repeat region and has been reported to modify transcriptional activity of 5-HTTLPR [27, 29]. 5-HTTLPR/rs25531 describes the triallelic polymorphism accounting for both 5-HTTLPR and $r s 25531$ genotypes. $X^{2}$-tests were used to calculate whether the distribution of genotype frequencies was in Hardy-Weinberg equilibrium (HWE).

\section{SLC6A4 promoter methylation analysis}

500 ng of genomic DNA was sodium bisulphite-converted using the EZ-96 DNA Methylation-Lightning MagPrep kit protocol (Zymo Research; Irvine, USA). The promoter-associated CpG island was targeted in our assay. This region is equivalent to amplicon 1 in a previous study [30]. A $335 \mathrm{bp}$ region (UCSC Human Genome Browser GRCh/hg_38 build: chr17: 30235734-30,236,068) [31] was amplified in triplicate, to account for variation in the PCR step [32], and methylation of $11 \mathrm{CpG}$ units, encompassing $20 \mathrm{CpG}$ sites, were quantified using the SEQUENOM MassARRAY EpiTYPER platform (Additional file 1: Table S1) [32]. Raw methylation data was generated on 361 samples. Mean methylation values were calculated from replicates within $10 \%$ of the median value (Martino et al. 2013). Participants with $<50 \%$ of methylation data available $(n=55)$ and outliers ( $>3$ times the interquartile range $(\mathrm{IQR}))(n=4)$ were excluded from further analysis. Following these quality control steps (Additional file 1: Figure S1), methylation data was obtained for a sub-sample of 302 participants, with no significant difference in depression status, age, sex and key variables (Table 1$)$ with the full ESPRIT cohort ( $p>0.05$ for all comparisons). 
Table 1 Characteristics of study participants according to depression status

\begin{tabular}{|c|c|c|c|}
\hline Characteristic $^{a}$ & No depression & Depression & $p$-value ${ }^{9}$ \\
\hline$n$ & 207 & 95 & - \\
\hline \multirow[t]{2}{*}{ Age (Mean \pm S.D.) } & $72.5 \pm 5.2$ & $74.6 \pm 5.7$ & 0.004 \\
\hline & \multicolumn{2}{|l|}{ Proportion (\%) } & \\
\hline Female & 55.1 & 68.4 & 0.028 \\
\hline Past major depressive disorder & 25.3 & 38.6 & 0.062 \\
\hline High education level ${ }^{b}$ & 38.2 & 25.3 & 0.028 \\
\hline Living alone & 20.9 & 43.2 & $<0.001$ \\
\hline Habitual alcohol drinkers (> 24 g/day) & 19.2 & 20.4 & 0.81 \\
\hline Habitual smokers ( $\geq 10$ pack years) & 35.6 & 34.4 & 0.84 \\
\hline Functional impairment ${ }^{c}$ & 5.31 & 13.7 & 0.013 \\
\hline Ischemic disease $^{d}$ & 10.6 & 22.1 & 0.008 \\
\hline Comorbidities $^{\mathrm{e}}$ & 12.1 & 29.5 & $<0.001$ \\
\hline Anxiety & 15.9 & 29.5 & 0.044 \\
\hline Dementia & 4.3 & 2.1 & 0.334 \\
\hline Impaired cognition $(\mathrm{MMSE}<26)^{f}$ & 13.6 & 11.6 & 0.63 \\
\hline Antidepressants & 3.38 & 12.6 & 0.002 \\
\hline Selective serotonin re-uptake inhibitor (SSRI) & 2.90 & 6.3 & 0.158 \\
\hline Tricyclic antidepressant (TCA) & 0.48 & 2.10 & 0.187 \\
\hline Other antidepressants & 0.00 & 4.20 & 0.003 \\
\hline Benzodiazepines & 4.83 & 9.47 & 0.123 \\
\hline Anxiolytics & 7.73 & 16.8 & 0.017 \\
\hline Psychotropic drugs & 4.83 & 11.6 & 0.032 \\
\hline Anticholinergics & 4.83 & 7.37 & 0.374 \\
\hline
\end{tabular}

${ }^{a}$ Not all participants with methylation data $(n=302)$ had information for each population characteristic listed, but missing data was $<2 \%$, with exception of anxiety $(20.5 \%)$ and past MDD $(33 \%)$

bunderwent post-secondary education of any type

'Unable to independently complete 2 items on both or either of the Instrumental Activities of Daily Living and Activities of Daily Living scales

${ }^{\mathrm{d}}$ History of angina pectoris, myocardial infarction, stroke, cardiovascular surgery and/or arteritis

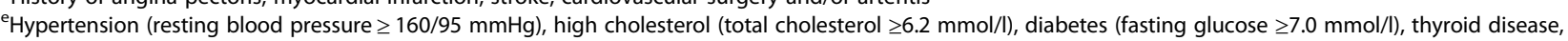

asthma, or recent cancer diagnosed within the last 2 years

fMMSE: Mini-Mental State Examination

${ }^{9} \mathrm{Chi}$-squared tests used to assess $p$-value for all variables except age, where a t-test was used

\section{Statistical analysis}

Statistical analyses were performed using the statistical software package Stata 14.1 (StataCorp, College Station, Texas, USA). Univariate analysis (analysis of variance, $t$-tests, $x^{2}$-tests) was performed to examine potential associations between genotype and DNA methylation, and between depression and DNA methylation. Additionally, these statistical tests were used to determine which population characteristics were associated with depression status (Table 1)and/ or DNA methylation levels independently. This step was performed to identify potential confounding factors of the association between DNA methylation and depression, which thus would be considered further in multivariate analysis. For associations between population characteristics and methylation, the significance threshold was set at a conservative level of $p<0.15$, to ensure that no potential confounding variables were omitted. Characteristics associated with both depression and methylation were considered in subsequent multivariate regression analysis as covariates. This included age, sex, living alone, functional impairment, ischemic disease, anxiety, comorbidities. Multivariate linear regression models were used to model the association between DNA methylation (outcome variable) and depression (predictor variable), while adjusting for the potential confounding factors. Potential modifying effects of genetic variants on the association between depression and DNA methylation were also investigated through the inclusion of a multiplicative interaction term in the multivariate models. When potential modifying effects of a specific genetic variant were found (at $p<0.15$ ), stratified analysis of methylation data across the genotype groups 
was performed. This involved $\mathrm{t}$-tests to determine the association between depression status and DNA methylation, in each genotype group of the specific variant. Sensitivity analysis excluding antidepressant users $(n=19)$ was performed as antidepressants may potentially mask depression status and independently influence methylation levels [33]. Sensitivity analysis excluding participants with past depression $(n=59)$ was also performed. Correction for multiple testing was performed using the Benjamini-Hochberg false discovery rate $(\mathrm{FDR})$ method $(\mathrm{FDR}=0.05)$.

\section{Results}

\section{Study population}

In this study of 302 participants, depressed individuals $(31.5 \%)$ were significantly more likely to be female, of older age, have a lower education level, live alone, be functionally impaired and have poorer health (ischemic pathologies and comorbidities), as compared to non-depressed participants. They were also more likely to be taking antidepressants. Characteristics of participants according to depression are shown in Table 1. All genotypes were in HWE $(p>0.05$ for all polymorphisms). Of the six genetic variants and one combined variant examined, only 5-HTTLPR was significantly associated with depression (Additional file 1: Table S2).

\section{Association between promoter DNA methylation and SLC6A4 genetic variants}

Overall, the methylation levels at the $335 \mathrm{bp}$ promoter region were relatively low, apart from CpG 25.26 which had the highest and most variable distribution of methylation (Fig. 1). Potential associations were observed between specific genetic variants and DNA methylation, independent of depression status (Table 2). In particular, homozygous GG genotypes of $r s 140700(p=0.019)$ and $r s 25531$ $(p=0.007)$ were significantly associated with higher methylation at CpG 16-20, while homozygous CC genotypes of $r s 25528(p=0.007)$ and $r s 6354(p=0.023)$ had significantly higher methylation at $\mathrm{CpG} 21$. However, it should be noted that applying a FDR Benjamini-Hochberg correction for multiple testing of $11 \mathrm{CpG}$ units and 6 polymorphisms $(\mathrm{FDR}=0.05)$ abolished these associations.

\section{Association between depression and methylation}

In unadjusted analysis, no significant differences in methylation were noted between depressed and non-depressed participants at any individual $\mathrm{CpG}$ units or the mean methylation across the region $(p>0.15$, except for CpG 3 with effect size $\Delta=0.31 \%$; $95 \% \mathrm{CI}: 0.04 ; 0.67 \%, p=0.084$ comparing depressed with non-depressed individuals). These findings did not change after inclusion of potential confounders in regression models (as stated in methods), or in sensitivity analysis excluding antidepressant users $(n=19)$ or participants with past depression $(n=59)$.

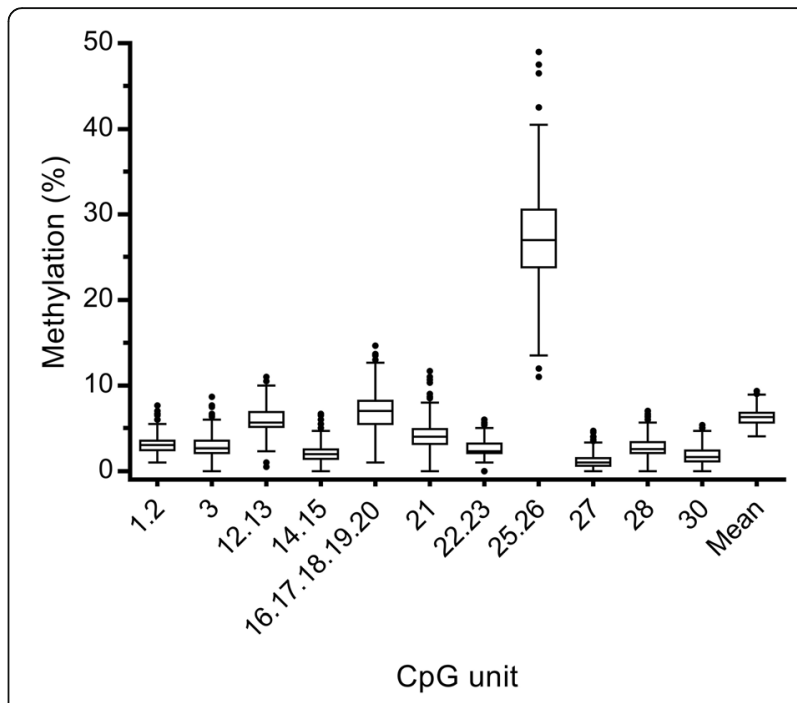

Fig. 1 Distribution of SLC6A4 methylation levels at each CpG unit and mean methylation levels across the region studied for all study participants. The box denotes the interquartile range (IQR: 25-75\% percentiles), the line shows the median and the whiskers are $1.5 \mathrm{x}$ IQR below the $25 \%$ percentile or above the $75 \%$ percentile

\section{Modification of the association between depression and methylation by SLC6A4 genotype}

Five SLC6A4 polymorphisms were found to potentially modify the association between depression and DNA methylation at multiple CpG units. 5-HTTLPR and 5-HTTLPR/rs25531 polymorphisms significantly modified the depression-methylation associations at both CpG 21 ( $p$-values for interaction term: 5-HTTLPR, $p=0.001$; 5-HTTLPR/rs25531, $p=0.006)$ and CpG 25.26 (5-HTTLPR, $p=0.064 ; 5-H T T L P R / r s 25531, p=0.030)$. In light of this, analysis was stratified by genotype, where clear differences in associations were observed.

Depression was significantly associated with lower methylation levels at CpG 21 and CpG 25.26, but only for individuals with the SS genotype of 5-HTTLPR (SS, $\Delta=-$ 1.60\%; 95\% CI: $-2.54 ;-0.65 \% ; p=0.001$, Fig. $2 \mathrm{a}$ and $\Delta=-$ 4.31\%; 95\% CI: -7.14 ; $-1.48 \%$; $p=0.004$, Fig. 2c respectively). In contrast, individuals with the LL genotype had highermethylation at CpG 21 (LL, $\Delta=0.88 \%$; 95\% CI: 0.10; $1.65 \% ; p=0.028$, Fig. 2a). Similar genotype dependent associations were likewise observed for 5-HTTLPR/rs25531 at CpG 21 (S'S', $\Delta=-1.10 \%$; 95\% CI: $-2.01 ;-0.20 ; p=0.018$, Fig. 2b) and CpG 25.26 (S'S', $\Delta=-4.39 \%$; 95\% CI: -6.95 ; 1.84\%; $p=0.001$, Fig. 2d) and at CpG 21 for L'L' genotype $(\Delta=1.18 \%$; $95 \%$ CI: $0.21 ; 2.15 ; p=0.019$, Fig. $2 b)$. These associations remained significant following multivariate adjustment for potential confounders, as shown in Table 3. Following correction for multiple testing (FDR $=0.05$ ), associations between depression and methylation at CpGs 21 (5-HTTLPR, SS) and 25.26 (5HTTLPR, SS; 5HTTLPR/ rs25531, S'S') remained significant. 
Table 2 Potential associations between SLC6A4 DNA methylation and genotype

\begin{tabular}{|c|c|c|c|c|c|}
\hline \multirow[t]{2}{*}{ CpG unit } & \multirow[t]{2}{*}{ Genetic variant } & \multicolumn{3}{|c|}{ Average methylation (\%) } & \multirow[t]{2}{*}{$p$-value } \\
\hline & & Major homozygote & Heterozygote & Minor homozygote & \\
\hline 3 & rs4251417 & GG (3.04) & GA (2.70) & AA (1.56) & 0.12 \\
\hline 14.15 & rs4251417 & GG (2.26) & GA (1.72) & AA (1.67) & 0.095 \\
\hline \multirow[t]{3}{*}{ 16.17.18.19.20 } & rs 140700 & GG (7.14) & GA (5.73) & AA (4.92) & 0.019 \\
\hline & rs6354 & AA (7.29) & AC (6.43) & CC (6.03) & 0.054 \\
\hline & rs25531 & AA (7.06) & AG (5.74) & GG (8.44) & 0.007 \\
\hline \multirow[t]{4}{*}{21} & rs 25528 & AA (3.54) & $A C(4.55)$ & CC (4.94) & 0.007 \\
\hline & rs4251417 & GG (4.03) & GA (3.17) & AA (3.06) & 0.085 \\
\hline & rs6354 & AA (3.53) & $A C(4.30)$ & CC (4.94) & 0.023 \\
\hline & 5-HTTLPR & LL (3.85) & SL (4.03) & SS (4.55) & 0.077 \\
\hline
\end{tabular}

${ }^{a} p$-values calculated by one-way ANOVAs and only those with $p<0.15$ shown

Three other genotypes were also found to potentially modify the associations between depression and methylation: $r 5140700$ (mean methylation; $p$-values for interaction term $=0.083), r s 6354(\mathrm{CpG} 25.26 ; p=0.061)$ and $r s 4251417$ (CpG 27, $p=0.026$ ). Following stratification; mean methylation was significantly lower in depressed patients with heterozygote $r s 140700$ genotype (GA, $\Delta=-1.17 \%$; 95\% CI: $-2.11 ;-0.24 \% ; p=0.021$; Additional file 1: Figure S2A); CPG 25.26 had highermethylation in depression for heterozygote $r s 6354$ genotype (AC, $\Delta=4.22 \%$; 95\% CI: 0.13; 8.32\%; $p=0.044$; Additional file 1: Figure S2B) and CpG 27 exhibited lowermethylation in depressed participants with homozygote $r s 4251417$ genotype (GG, $\Delta=-0.40 \%$; $95 \% \mathrm{CI}$ :
$-0.74 ;-0.062 \% ; p=0.021$; Additional file 1: Figure S2C). However, none of these associations remained significant in multivariate linear regression models (data not shown).

The overall relationships between SLC6A4 genetic variants, promoter methylation and depression are shown in Fig. 3.

\section{Discussion}

Our study investigated the relationship between SLC6A4 promoter methylation and six polymorphisms (5-HTTLPR, rs 140700, rs42151417, rs6354, rs25528, rs25531), plus a combined variant (5-HTTLPR/rs25531) independently and in the context of late-life depression. We found marginal
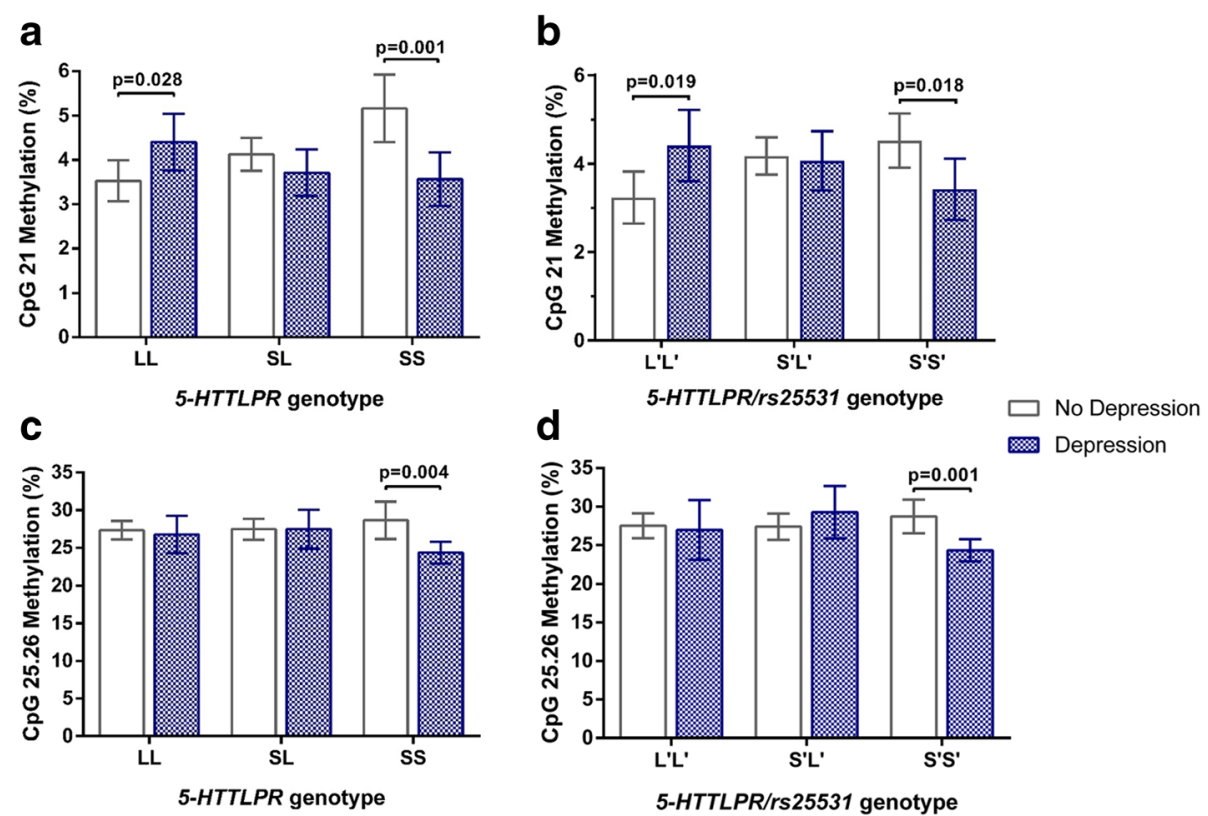

Fig. 2 DNA methylation at CpG units 21 and 25.26 according to depression status, stratified by serotonin transporter (SLC6A4) genotypes: 5 HTTLPR and 5-HTTLPR/rs25531. a CpG 21, 5-HTTLPR $(n=274) ;(\mathbf{b})$ CpG 21, 5-HTTLPR/rs25531 ( $n=210) ;(\mathbf{c})$ CpG 25.26, 5-HTTLPR $(n=234) ;(\mathbf{d})$ CpG 25.26, 5-HTTLPR/rs25531 $(n=182)$. Data presented as mean methylation $\pm 95 \%$ Cl. T-tests were used to calculate $p$-values, with significant associations at $p<0.05$ indicated in the figure 
Table 3 Adjusted associations between depression and SLC6A4 promoter methylation, stratified by 5-HTTLPR or 5-HTTLPR/rs25531 genotype

\begin{tabular}{|c|c|c|c|c|c|c|}
\hline \multirow[t]{2}{*}{ CpG unit } & \multirow[t]{2}{*}{ Genotype } & \multirow[t]{2}{*}{ Variables } & \multicolumn{2}{|l|}{ Unadjusted } & \multicolumn{2}{|l|}{ Adjusted $^{a}$} \\
\hline & & & $\beta(\mathrm{SE})$ & $p$-value & $\beta(\mathrm{SE})$ & $p$-value \\
\hline \multirow[t]{18}{*}{21} & \multirow[t]{4}{*}{ 5-HTTLPR (LL) } & Depression & \multirow[t]{4}{*}{$0.24(0.39)$} & \multirow[t]{4}{*}{0.026} & $0.28(0.41)$ & 0.016 \\
\hline & & Female sex & & & $-0.092(0.39)$ & 0.39 \\
\hline & & Age (yrs) & & & $0.024(0.036)$ & 0.83 \\
\hline & & Antidepressants & & & $-0.15(0.83)$ & 0.18 \\
\hline & \multirow[t]{5}{*}{ 5-HTTLPR (SS) } & Depression & \multirow[t]{5}{*}{$-0.38(0.52)$} & \multirow[t]{5}{*}{0.004} & $-0.44(0.54)$ & 0.001 \\
\hline & & Female sex & & & $-0.17(0.58)$ & 0.22 \\
\hline & & Age (yrs) & & & $-0.03(0.068)$ & 0.82 \\
\hline & & Antidepressant & & & $0.13(0.96)$ & 0.33 \\
\hline & & Living alone & & & $0.38(0.69)$ & 0.018 \\
\hline & \multirow[t]{4}{*}{ 5-HTTLPR/rs25531 (L'L) } & Depression & \multirow[t]{4}{*}{$0.33(0.49)$} & \multirow[t]{4}{*}{0.019} & $0.36(0.53)$ & 0.019 \\
\hline & & Female sex & & & $0.074(0.48)$ & 0.60 \\
\hline & & Age (yrs) & & & $-0.005(0.057)$ & 0.97 \\
\hline & & Antidepressant & & & $-0.093(1.3)$ & 0.54 \\
\hline & \multirow[t]{5}{*}{ 5-HTTLPR/rs25531 (S'S') } & Depression & \multirow[t]{5}{*}{$-0.28(0.49)$} & \multirow[t]{5}{*}{0.027} & $-0.30(0.50)$ & 0.023 \\
\hline & & Female sex & & & $-0.14(0.49)$ & 0.29 \\
\hline & & Age (yrs) & & & $-0.22(0.59)$ & 0.097 \\
\hline & & Antidepressant & & & $0.098(0.87)$ & 0.44 \\
\hline & & Living alone & & & $0.27(0.60)$ & 0.056 \\
\hline \multirow[t]{8}{*}{25.26} & \multirow[t]{4}{*}{ 5-HTTLPR (SS) } & Depression & \multirow[t]{4}{*}{$-0.37(1.58)$} & \multirow[t]{4}{*}{0.009} & $-0.31(1.68)$ & 0.038 \\
\hline & & Sex & & & $-0.26(1.65)$ & 0.068 \\
\hline & & Age (yrs) & & & $-0.076(0.20)$ & 0.60 \\
\hline & & Antidepressant & & & $-0.087(3.06)$ & 0.56 \\
\hline & \multirow[t]{4}{*}{ 5-HTTLPR/rs25531 (S'S') } & Depression & \multirow[t]{4}{*}{$-0.37(1.53)$} & \multirow[t]{4}{*}{0.006} & $-0.31(1.52)$ & 0.020 \\
\hline & & Sex & & & $-0.19(1.46)$ & 0.13 \\
\hline & & Age (yrs) & & & $-0.26(0.18)$ & 0.046 \\
\hline & & Antidepressant & & & $-0.11(2.71)$ & 0.39 \\
\hline
\end{tabular}

${ }^{a}$ Adjusted for age, sex and antidepressant use, plus confounding factors (see methods) which remained significant in the final models at $p<0.15$

and nominally significant evidence that six genetic variants influenced site-specific methylation at four out of $11 \mathrm{CpG}$ units. Whilst methylation was not independently associated with depression, specific genotypes were found to modify the association between depression and methylation at several CpG units. In particular, for individuals with the SS or S'S genotypes of 5-HTTLPR and 5-HTTLPR/rs25531 respectively, depression was significantly associated with lowermethylation at CpG 21 and CpG 25.26. On the other hand, for individuals carrying the LL or L'L' genotypes, depression was nominally associated with higher methylation at CpG 21. These findings were not confounded by sex, age, antidepressant use, or other factors examined including living situation and comorbidities.

Differential SLC6A4 methylation at the promoter CpG island has been correlated with risk factors and adversities related to depression. Associations has been observed between maternal depression and decreased infant SLC6A4 promoter methylation [34]. In adults, increased methylation has been associated with childhood trauma [35] and stress (early life and recent) [30, 36]. An inverse correlation between SLC6A4 mRNA levels and promoter methylation has been demonstrated [11]. Several studies support our findings, reporting no association between SLC6A4 methylation in blood and depression in adults, in either Caucasian [12] or three Asian $(n=108 ; n=286 ; n=100)[14,15,17]$ populations, as well as in buccal mucosa from Caucasian adolescents $(n=150)$ [16] and EBV-transformed lymphoblasts ( $n$ $=192$ ) [18]. In contrast, three studies found positive associations between peripheral SLC6A4 methylation in blood and depression in Caucasian $(n=57)$ [13] and Asian adults ( $n=151 ; n=84)[19,20]$, two of which had overlapping assay regions with our study $[19,20]$. Interestingly, Shi et al. (2016) found significantly highermethylation at two CpG 


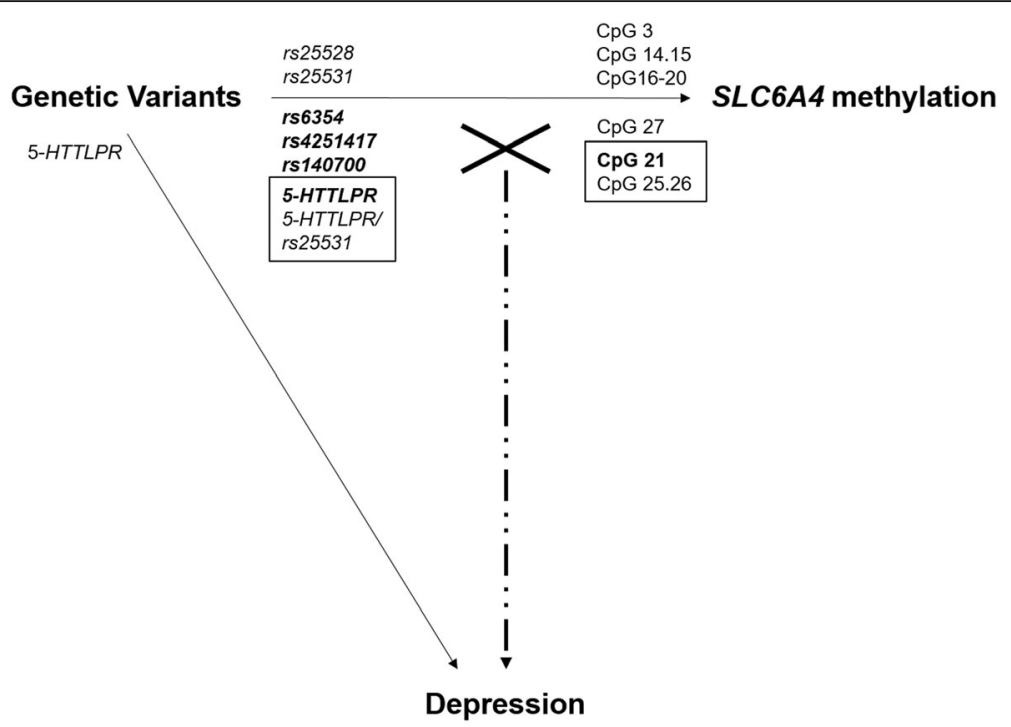

Fig. 3 Diagram of relationships between SLC6A4 genetic variants, promoter methylation and depression. Solid lines indicate an association. The X denotes the interaction between genetic variants and SLC6A4 methylation in association with depression (dot-dash line). Bolded genetic variants or DNA methylation sites in boxes were independently associated, but also interacted to influence depression risk. Interactions which remained significant following FDR correction are boxed

sites $(\Delta=2.52$ and 0.15$)$ corresponding to $\mathrm{CpG} 25.26$ in our study, which we failed to find, despite this unit having the highest level and variability of methylation.

It is increasingly clear that genetic variation plays a critical role in the regulation of DNA methylation [21]. Such loci, referred to as methylation quantitative trait loci (mQTLs), may also modify the association between DNA methylation risk of disease $[37,38]$. Previous studies that have investigated the extent to which SLC6A4 genotype can influence DNA methylation in the context of depression, have focused primarily on the 5-HTTLPR polymorphism. Several reported no significant association with mean methylation $[12,16,17]$, which is supported by our findings. However, we did observe a trend for an association between 5-HTTLPR SS genotype and higherCpG 21 methylation $(p=0.077)$, which is in concordance with a study in post-stroke depression [15]. In addition, rs25531, which has been shown to modify the functionality of 5-HTTLPR [27, 29] was also associated with site-specific methylation at CpG unit 16-20. Here we have shown for the first time that four other polymorphisms (rs4251417, rs140700, rs6354 and rs25528) in SLC6A4 may potentially regulate DNA methylation in the region.

Modifying effects of 5-HTTLPR genotype on the association between SLC6A4 methylation and several depression-related adversities, including childhood abuse [12] and stress [36], have been demonstrated previously. The few studies which have investigated this in the context of depression, have found that the $\mathrm{S}$ allele in combination with higherSLC6A4 methylation increased the risk of depressive symptoms in adolescents [16] and adults following stroke [15]. This contrasts with our current study which observed lower methylation at CpG units 21 and 25.26 in depressed older individuals with the SS genotype. However, a recent study by Iga et al. (2016) (average age: $42.2-45.0$ years) found that the $\mathrm{L}$ allele was associated with higherperipheral blood methylation in depressed patients [13]. More broadly, as an inverse correlation exists between SLC6A4 methylation and mRNA levels [11], our finding of decreased methylation in depressed individuals is consistent with the observation of increased peripheral SLC6A4 mRNA in un-medicated MDD patients [39-41].

The vast majority of epigenetic studies of 5-HTTLPR did not consider $S L$ genotype individually, which makes it hard to determine the real (in)consistency of data [8]. Similar to Iga et al., we found highermethylation at CpG 21 in depressed older individuals with the LL genotype, although this was only nominally significant in our study. Interestingly, previous findings also indicate that age can influence the association between 5-HTTLPR and mental health [8].

Given the larger sample size, our findings further strengthen the evidence that 5-HTTLPR plays a role in modifying the association of methylation with depression. We also found significant modifying effects from the triallelic 5-HTTLPR/rs 25531 polymorphism. Whilst 5-HTTLPR/rs25531 modification effects have not been studied in relation to the $\mathrm{CpG}$ island, a recent study found that carriers of the $S^{\prime}$ allele had lowermethylation at a neighboring Alu retrotransposon (AluJb) in association with stress [42], which is in a similar direction of effect found in our study. 
This is also the first study to examine the potential modifying effects of other polymorphisms throughout the SLC6A4 gene on the depression-methylation association. Here, we report modifying effects from rs140700, rs4251417, rs6354, but these associations did not remain significant following multivariate adjustment. This may be because of the relatively small sample size with these genotypes, in particular because there were too few minor homozygotes to include in the analysis, with the comparison instead been only between major homozygotes and heterozygotes. Therefore, a larger sample size able to capture the minor homozygote is needed to further investigate these associations. Overall, the effects of genotype and methylation may combine to exert another layer of regulation in modifying risk of depression. Further investigation is needed to examine the underlying mechanisms and its function in influencing depression risk.

Our study of 302 participants is larger than all previous studies investigating SLC6A4 methylation and genetic variation in depression. However only subtle differences in DNA methylation levels have been observed in peripheral tissues in association with psychiatric disorders, suggesting that an even larger sample size may be required to fully reveal true associations. We were able to consider several polymorphisms throughout the gene in combination with promoter methylation in our study, and adjust for a wide variety of confounding factors including sex, age and antidepressant use. Our participants were from the general population, thus making our findings more generalisable, as opposed to studies focused only on depressed hospital patients. Late-life depression covers a range of mild to severe depressive symptoms [43], so the CES-D scale to assess depressive symptoms, together with the DSM-IV classification of MDD (American Psychiatric Association, 1994), has helped ensure non-depressed individuals in this study did not have significant levels of sub-clinical symptomatology. Whilst our results may be generalisable to the older population, it may not be the case for earlier onset depression and non-Caucasian populations. Contributors to the etiology of depression may vary by age of onset, with late-life depression more frequently comorbid with physical and psychiatric conditions such as cardiovascular disease and stroke [44]. Depressive symptoms are also more frequent amongst the oldest old, which may be explained by factors associated with aging, such as higher proportion of women and increased physical impairment [44]. This is consistent with our finding that depressed individuals are significantly more likely to be female, older and functionally impaired (Table 1). DNA methylation patterns have been reported to vary with age, sex and ethnicity $[45,46]$. Specifically, global hypomethylation has been reported in females [46] and with increasing age [45]. Hence, decreases in SLC6A4 methylation, as observed in this study, may be specifically associated with late-life depression.
Other limitations to our study are the cellular heterogeneity of blood, the cross-sectional design of this study and potential residual confounding from factors for which information was not available or collected. Our study focused on white blood cells, which contain a heterogenous assortment of cell types. Given the cell-type-specific nature of methylation, variation in cellular composition may lead to distinct methylation profiles between cell types, potentially confounding methylation-related analyses [47]. This may account for the lack of associations observed between depression and SLC6A4 methylation in our study. Cellular heterogeneity cannot be controlled for in a candidate gene study such as ours. Epigenome-wide association studies, on the other hand, have the ability to computationally adjust for cellular heterogeneity [48], with the added advantage of being able to interrogate large proportions of the (epi)genome without an a priori hypothesis.

Finally, as an association study, we are unable to draw any conclusions about the functionality or causality of our findings. Using peripheral methylation to examine a brainbased disorder has its limitations, as methylation profiles can also be distinct across different tissues. A few studies have reported correlations between DNA methylation levels in blood and post-mortem brain tissue, although these are likely to be gene-specific $[49,50]$. Changes in peripheral tissues, such as in inflammatory markers, have been observed in depression, therefore becoming increasingly recognised as a systemic disease [51, 52]. Further, both SLC6A4 methylation and genetic variants have been correlated with brain structural changes, including the hippocampus and corpus callosum, in depressed individuals [12, 53-55]. As such, our study may provide support for SLC6A4 methylation as a biomarker of depression, indicating that such a biomarker would need to consider SLC6A4 methylation in combination with genetic variation.

\section{Conclusion}

Our study of late-life depression did not find any strong evidence for an independent association between SLC6A4 promoter methylation and depression, however this may be modified by underlying genetic variants in the region. Further investigation is needed to examine the mechanisms behind such interactions, and replication in larger, independent and longitudinal studies are needed to help confirm these findings.

\section{Additional file}

Additional file 1: Table S1. Individual CpG units assayed and analysed in this study. Table S2. Frequency of SLC6A4 genotypes according to depression status in the study population. Figure S1. Flowchart of the quality control process following the generation of SLC6A4 methylation data. Figure S2. Differences in DNA methylation according to depression status, stratified by SLC6A4 genotypes. (DOCX $421 \mathrm{~kb}$ ) 


\section{Abbreviations}

CES-D: Centre for Epidemiological Studies Depression Scale; DSMIV: Diagnostic and Statistical Manual of Mental Disorders-IV; HWE: HardyWeinberg equilibrium; IQR: Interquartile range; MDD: Major depressive disorder; MINI: Mini International Neuropsychiatric Interview; mQTL: Methylation quantitative trait loci; SNP: Single nucleotide polymorphism; SSRI: Selective serotonin re-uptake inhibitor; VNTR: Variable number tandem repeat

\section{Acknowledgements}

We thank all ESPRIT study participants, and Dr. Benjamin Ong for assistance with the Sequenom MassARRAY platform.

\section{Funding}

The ESPRIT project is financed by the regional government of LanguedocRoussillon, the Agence Nationale de la Recherche Project 07 LVIE 004, and an unconditional grant from Norvartis. This work was also supported by the National Health and Medical Research Council, through a Senior Research Fellowship (APP1045161 to RS); the Murdoch Children's Research Institute (studentship to DL) and the Victorian Government's Operational Infrastructure Support Program. The funders had no role in the design and conduct of the study; in data collection, management, analysis or interpretation of the data and were not involved with the writing, preparation, review or approval of the manuscript.

\section{Availability of data and materials}

The datasets analysed during the current study are available from the corresponding author (JR) on reasonable request.

\section{Authors' contributions}

MLA and KR lead the ESPRIT study and the collection of data. JR set up the study, DL processed all biological samples, generated the methylation data and performed all data analyses. JR and RS were involved in the interpretation of the data. DL drafted the manuscript and all authors were involved in its revision and gave final approval to the submitted manuscript.

\section{Ethics approval and consent to participate}

This study has been approved by the Ethical Committee of University Hospital of Kremlin-Bicêtre, France. All participants provided written informed consent before participating in the study.

\section{Consent for publication}

Not applicable.

\section{Competing interests}

Joanne Ryan is currently acting as an Associate Editor for BMC Psychiatry. All other authors declare that they have no competing interests.

\section{Publisher's Note}

Springer Nature remains neutral with regard to jurisdictional claims in published maps and institutional affiliations.

\begin{abstract}
Author details
${ }^{1}$ Cancer \& Disease Epigenetics, Murdoch Children's Research Institute, Royal Children's Hospital, Parkville, VIC, Australia. ${ }^{2}$ Department of Paediatrics, University of Melbourne, Parkville, VIC, Australia. ${ }^{3}$ INSERM, Univ Montpellier, Neuropsychiatry: Epidemiological and Clinical Research, Montpellier, France. ${ }^{4}$ Centre for Clinical Brain Sciences, University of Edinburgh, Edinburgh, UK. ${ }^{5}$ Department of Epidemiology and Preventive Medicine, Monash University, Level 5, The Alfred Centre, 99 Commercial Road, Melbourne 3004, Australia.
\end{abstract}

Received: 22 February 2018 Accepted: 13 August 2018

Published online: 04 September 2018

\section{References}

1. Albert PR, Benkelfat C, Descarries $L$. The neurobiology of depression--revisiting the serotonin hypothesis. I. Cellular and molecular mechanisms. Philos Trans R Soc Lond Ser B Biol Sci. 2012;367(1601):2378-81.

2. Belmaker RH, Agam G. Major depressive disorder. N Engl J Med. 2008; 358(1):55-68
3. Albert PR, Benkelfat C. The neurobiology of depression--revisiting the serotonin hypothesis. II. Genetic, epigenetic and clinical studies. Philos Trans R Soc Lond Ser B Biol Sci. 2013;368(1615):20120535.

4. Ramamoorthy S, Bauman AL, Moore KR, Han H, Yang-Feng T, Chang AS, Ganapathy V, Blakely RD. Antidepressant- and cocaine-sensitive human serotonin transporter: molecular cloning, expression, and chromosomal localization. Proc Natl Acad Sci U S A. 1993;90(6):2542-6.

5. Bradley SL, Dodelzon K, Sandhu HK, Philibert RA. Relationship of serotonin transporter gene polymorphisms and haplotypes to mRNA transcription. Am J Med Genet B Neuropsychiatr Genet. 2005;136B(1):58-61.

6. Lesch KP, Bengel D, Heils A, Sabol SZ, Greenberg BD, Petri S, Benjamin J, Muller CR, Hamer DH, Murphy DL. Association of anxiety-related traits with a polymorphism in the serotonin transporter gene regulatory region. Science. 1996;274(5292):1527-31.

7. Clarke H, Flint J, Attwood AS, Munafo MR. Association of the 5- HTTLPR genotype and unipolar depression: a meta-analysis. Psychol Med. 2010; 40(11):1767-78.

8. Ancelin ML, Ryan J. 5-HTTLPR x stress hypothesis: is the debate over? Mol Psychiatry. 2017. https://doi.org/10.1038/mp.2017.195. [Epub ahead of print]

9. Booij L, Wang D, Levesque ML, Tremblay RE, Szyf M. Looking beyond the DNA sequence: the relevance of DNA methylation processes for the stressdiathesis model of depression. Philos Trans R Soc Lond Ser B Biol Sci. 2013; 368(1615):20120251.

10. Booij L, Tremblay RE, Szyf M, Benkelfat C. Genetic and early environmental influences on the serotonin system: consequences for brain development and risk for psychopathology. J Psychiatry Neurosci. 2015;40(1):5-18.

11. Philibert R, Madan A, Andersen A, Cadoret R, Packer H, Sandhu H. Serotonin transporter mRNA levels are associated with the methylation of an upstream CpG island. Am J Med Genet B Neuropsychiatr Genet. 2007; 144B(1):101-5

12. Booij L, Szyf M, Carballedo A, Frey EM, Morris D, Dymov S, Vaisheva F, Ly V, Fahey C, Meaney J, et al. DNA methylation of the serotonin transporter gene in peripheral cells and stress-related changes in hippocampal volume: a study in depressed patients and healthy controls. PLoS One. 2015;10(3):e0119061.

13. Iga J, Watanabe SY, Numata S, Umehara H, Nishi A, Kinoshita M, Inoshita M, Shimodera S, Fujita H, Ohmori T. Association study of polymorphism in the serotonin transporter gene promoter, methylation profiles, and expression in patients with major depressive disorder. Hum Psychopharmacol. 2016; 31(3):193-9.

14. Kang HJ, Kim JM, Stewart R, Kim SY, Bae KY, Kim SW, Shin IS, Shin MG, Yoon JS. Association of SLC6A4 methylation with early adversity, characteristics and outcomes in depression. Prog Neuro-Psychopharmacol Biol Psychiatry. 2013;44:23-8.

15. Kim JM, Stewart R, Kang HJ, Kim SW, Shin IS, Kim HR, Shin MG, Kim JT, Park MS, Cho KH, et al. A longitudinal study of SLC6A4 DNA promoter methylation and poststroke depression. J Psychiatr Res. 2013;47(9):1222-7.

16. Olsson CA, Foley DL, Parkinson-Bates M, Byrnes G, McKenzie M, Patton GC, Morley R, Anney RJ, Craig JM, Saffery R. Prospects for epigenetic research within cohort studies of psychological disorder: a pilot investigation of a peripheral cell marker of epigenetic risk for depression. Biol Psychol. 2010; 83(2):159-65.

17. Okada S, Morinobu S, Fuchikami M, Segawa M, Yokomaku K, Kataoka T, Okamoto Y, Yamawaki S, Inoue T, Kusumi I, et al. The potential of SLC6A4 gene methylation analysis for the diagnosis and treatment of major depression. J Psychiatr Res. 2014:53:47-53.

18. Philibert RA, Sandhu H, Hollenbeck N, Gunter T, Adams W, Madan A. The relationship of $5 \mathrm{HTT}$ (SLC6A4) methylation and genotype on mRNA expression and liability to major depression and alcohol dependence in subjects from the lowa adoption studies. Am J Med Genet B Neuropsychiatr Genet. 2008;147B(5):543-9.

19. Shi M, Sun H, Xu Y, Wang Z, Cui H, Wang C, Liu W, An G, Hu J. Methylation status of the serotonin transporter promoter $\mathrm{CpG}$ Island is associated with major depressive disorder in Chinese Han population: a case-control study. J Nerv Ment Dis. 2016;205(8):641-6.

20. Zhao J, Goldberg J, Bremner JD, Vaccarino V. Association between promote methylation of serotonin transporter gene and depressive symptoms: a monozygotic twin study. Psychosom Med. 2013;75(6):523-9.

21. Gaunt TR, Shihab HA, Hemani G, Min JL, Woodward G, Lyttleton O, Zheng J, Duggirala A, McArdle WL, Ho K, et al. Systematic identification of genetic influences on methylation across the human life course. Genome Biol. 2016;17:61. 
22. Ritchie K, Artero S, Beluche I, Ancelin ML, Mann A, Dupuy AM, Malafosse A, Boulenger JP. Prevalence of DSM-IV psychiatric disorder in the French elderly population. Br J Psychiatry. 2004;184:147-52.

23. Association AP. Diagnostic and statistical manual of mental disorders. 5th ed; 2013.

24. Beekman AT, Deeg DJ, Van Limbeek J, Braam AW, De Vries MZ, Van Tilburg W. Criterion validity of the Center for Epidemiologic Studies Depression scale (CES-D): results from a community-based sample of older subjects in the Netherlands. Psychol Med. 1997;27(1):231-5.

25. Radloff LS. The CES-D scale: a self-report depression scale for research in the general population. Appl Psychol Meas. 1977;1:385:385-401.

26. Ritchie K, Jaussent I, Stewart R, Dupuy AM, Courtet P, Ancelin ML, Malafosse A. Association of adverse childhood environment and 5-HTTLPR genotype with late-life depression. J Clin Psychiatry. 2009;70(9):1281-8.

27. Wray NR, James MR, Gordon SD, Dumenil T, Ryan L, Coventry WL, Statham DJ, Pergadia ML, Madden PA, Heath AC, et al. Accurate, large-scale genotyping of 5 HTTLPR and flanking single nucleotide polymorphisms in an association study of depression, anxiety, and personality measures. Biol Psychiatry. 2009;66(5):468-76.

28. Raitio M, Perälä A, Harinen R, Lampinen J. Validation of KASPar ${ }^{\mathrm{TM}}$ dual FRET based SNP genotyping assay. Thermo Fisher Scientific. 2012:1-5.

29. Wendland JR, Martin BJ, Kruse MR, Lesch KP, Murphy DL. Simultaneous genotyping of four functional loci of human SLC6A4, with a reappraisal of 5-HTTLPR and rs25531. Mol Psychiatry. 2006;11(3):224-6.

30. Duman EA, Canli T. Influence of life stress, 5-HTTLPR genotype, and SLC6A4 methylation on gene expression and stress response in healthy Caucasian males. Biol Mood Anxiety Disord. 2015;5:2.

31. Kent WJ, Sugnet CW, Furey TS, Roskin KM, Pringle TH, Zahler AM, Haussler D. The human genome browser at UCSC. Genome Res. 2002;12(6):996-1006.

32. Coolen MW, Statham AL, Gardiner-Garden M, Clark SJ. Genomic profiling of CpG methylation and allelic specificity using quantitative high-throughput mass spectrometry: critical evaluation and improvements. Nucleic Acids Res. 2007;35(18):e119.

33. Menke A, Binder EB. Epigenetic alterations in depression and antidepressant treatment. Dialogues Clin Neurosci. 2014;16(3):395-404

34. Devlin AM, Brain U, Austin J, Oberlander TF. Prenatal exposure to maternal depressed mood and the MTHFR C677T variant affect SLC6A4 methylation in infants at birth. PLoS One. 2010;5(8):e12201.

35. Wang D, Szyf M, Benkelfat C, Provencal N, Turecki G, Caramaschi D, Cote SM, Vitaro F, Tremblay RE, Booij L. Peripheral SLC6A4 DNA methylation is associated with in vivo measures of human brain serotonin synthesis and childhood physical aggression. PLoS One. 2012;7(6):e39501.

36. Alexander N, Wankerl M, Hennig J, Miller R, Zankert S, Steudte-Schmiedgen $\mathrm{S}$, Stalder T, Kirschbaum C. DNA methylation profiles within the serotonin transporter gene moderate the association of 5-HTTLPR and cortisol stress reactivity. Transl Psychiatry. 2014;4:e443.

37. Rakyan VK, Down TA, Balding DJ, Beck S. Epigenome-wide association studies for common human diseases. Nat Rev Genet. 2011;12(8):529-41.

38. Zhi D, Aslibekyan S, Irvin MR, Claas SA, Borecki IB, Ordovas JM, Absher DM, Arnett DK. SNPs located at CpG sites modulate genome-epigenome interaction. Epigenetics. 2013;8(8):802-6.

39. Belzeaux R, Azorin JM, Ibrahim EC. Monitoring candidate gene expression variations before, during and after a first major depressive episode in a 51 year-old man. BMC Psychiatry. 2014;14:73.

40. Iga J, Ueno S, Yamauchi K, Motoki I, Tayoshi S, Ohta K, Song H, Morita K, Rokutan K, Ohmori T. Serotonin transporter mRNA expression in peripheral leukocytes of patients with major depression before and after treatment with paroxetine. Neurosci Lett. 2005;389(1):12-6.

41. Tsao CW, Lin YS, Chen CC, Bai CH, Wu SR. Cytokines and serotonin transporter in patients with major depression. Prog Neuro-Psychopharmacol Biol Psychiatry. 2006;30(5):899-905.

42. Schneider I, Kugel H, Redlich R, Grotegerd D, Burger C, Burkner PC, Opel N, Dohm K, Zaremba D, Meinert S, et al. Association of Serotonin Transporter Gene AluJb methylation with major depression, amygdala responsiveness, 5-HTTLPR/rs25531 polymorphism, and stress. Neuropsychopharmacology. 2017;43(6):1308-16.

43. Fiske A, Wetherell $J$, Gatz M. Depression in older adults. Annu Rev Clin Psychol. 2009;5:363-89.

44. Blazer DG. Depression in late life: review and commentary. J Gerontol A Biol Sci Med Sci. 2003;58(3):249-65.

45. Johnson AA, Akman K, Calimport SR, Wuttke D, Stolzing A, de Magalhaes JP. The role of DNA methylation in aging, rejuvenation, and age-related disease. Rejuvenation Res. 2012;15(5):483-94.
46. Zhang FF, Cardarelli R, Carroll J, Fulda KG, Kaur M, Gonzalez K, Vishwanatha JK, Santella RM, Morabia A. Significant differences in global genomic DNA methylation by gender and race/ethnicity in peripheral blood. Epigenetics. 2011:6(5):623-9.

47. Januar V, Saffery R, Ryan J. Epigenetics and depressive disorders: a review of current progress and future directions. Int J Epidemiol. 2015;44(4):1364-87.

48. Jaffe $A E$, Irizarry RA. Accounting for cellular heterogeneity is critical in epigenome-wide association studies. Genome Biol. 2014;15(2):R31.

49. Davies MN, Volta M, Pidsley R, Lunnon K, Dixit A, Lovestone S, Coarfa C, Harris RA, Milosavljevic A, Troakes C, et al. Functional annotation of the human brain methylome identifies tissue-specific epigenetic variation across brain and blood. Genome Biol. 2012;13(6):R43.

50. Horvath S, Zhang Y, Langfelder P, Kahn RS, Boks MP, van Eijk K, van den Berg LH, Ophoff RA. Aging effects on DNA methylation modules in human brain and blood tissue. Genome Biol. 2012;13(10):R97.

51. O'Donovan A, Hughes BM, Slavich GM, Lynch L, Cronin MT, O'Farrelly C, Malone KM. Clinical anxiety, cortisol and interleukin-6: evidence for specificity in emotion-biology relationships. Brain Behav Immun. 2010; 24(7):1074-7.

52. Thomson CA, McColl A, Cavanagh J, Graham GJ. Peripheral inflammation is associated with remote global gene expression changes in the brain. J Neuroinflammation. 2014;11:73.

53. Frodl T, Szyf M, Carballedo A, Ly V, Dymov S, Vaisheva F, Morris D, Fahey C, Meaney J, Gill M, et al. DNA methylation of the serotonin transporter gene (SLC6A4) is associated with brain function involved in processing emotional stimuli. J Psychiatry Neurosci. 2015;40(5):296-305.

54. Taylor WD, Steffens DC, Payne ME, MacFall JR, Marchuk DA, Svenson IK, Krishnan KR. Influence of serotonin transporter promoter region polymorphisms on hippocampal volumes in late-life depression. Arch Gen Psychiatry. 2005;62(5):537-44.

55. Won E, Choi S, Kang J, Kim A, Han KM, Chang HS, Tae WS, Son KR, Joe $\mathrm{SH}$, Lee MS, et al. Association between reduced white matter integrity in the corpus callosum and serotonin transporter gene DNA methylation in medication-naive patients with major depressive disorder. Transl Psychiat. 2016;6

\section{Ready to submit your research? Choose BMC and benefit from:}

- fast, convenient online submission

- thorough peer review by experienced researchers in your field

- rapid publication on acceptance

- support for research data, including large and complex data types

- gold Open Access which fosters wider collaboration and increased citations

- maximum visibility for your research: over $100 \mathrm{M}$ website views per year

At $\mathrm{BMC}$, research is always in progress.

Learn more biomedcentral.com/submissions 